\title{
Investigating the Civil Responsibility of Managers and Lifeguards against Swimmers
}

\author{
Akbar Bashiri ${ }^{1 *}$, Behnam Ramazani ${ }^{2}$ and Mahdi Mohammad Zadeh ${ }^{3}$ \\ 1 Corresponding Author: Assistant Professor, Department of Law, Maragheh Branch, Islamic Azad University, Maragheh, Iran. \\ 2 PhD Student, Department of Law, Maragheh Branch, Islamic Azad University, Maragheh, Iran. \\ 3 PhD Student, Department of Law, Maragheh Branch, Islamic Azad University, Maragheh, Iran.
}

\begin{abstract}
Civil responsibility is an issue of civil rights covering a significant portion of current legal literature. Civil responsibility has been defined as a person's legal commitment for compensation of the damage (whether being directly caused by the person or caused by his/her action) he/she has inflicted on another person. In case of lifeguards, this responsibility is due to their fault and if the cause of harm is due to the fault of the lifeguard, he/she will have a compulsory guarantee for compensation. Considering this content, under certain conditions, sport agents including lifeguards are responsible for compensation of damages caused by their fault. Legal and real entities engaged with sports not only are responsible for adherence to contractual assignments, but also are required to adhere to non-contractual obligations that are generally associated with societal traditions and customs or special characteristics of specific sporting fields. Civil responsibility law which is one of the most important and comprehensive branches of law, lacks normative system and adaptive regulations in Iran. In past, this type of responsibility was considered as a subsidiary subject in civil rights, however nowadays it is practically and theoretically considered as the most significant component of obligations. On the other nowadays civil responsibility plays a role in every single social activity.

Keywords: civil responsibility, swimming pool, responsibility of sport managers, responsibility of lifeguards, fault
\end{abstract}

\section{INTRODUCTION}

\section{Code of ethics of lifeguards}

In verse 36 of sura of Maede, Allah has said that whoever saves a human from dying saves the whole world. In addition, Prophet Muhammad has said: Instructing the job of prophets. Lifeguarding or lifesaving has a very special status and is considered as a divine occupation. Those young men and women who take training courses in lifesaving and healing and rescue fields prepare themselves for saving humans' life. In general, those who are oriented towards these occupations are naturally believers in good traits and athletic spirits. Some of the aspects of their code of ethics include:

1 - Discipline at work

2 - Enthusiasm for providing service for lovers of water sports

3- Precision in performance of tasks to the extent of sacrificing for saving lives of humans

4 - Politeness and adherence to ethics at work

With respect to its great deal of implication in disputes, civil responsibility has become one of the most important branches of civil rights. Considering that sport spaces are exclusively effective on ethics of people especially the youths, we are required to codify certain sport rights and civil respon- 
sibility regulations for sport managers and coaches in order to be able to recognize the party responsible for compensation of damages in case of violations. In a case in which a person is responsible for compensation of a damage inflicted on someone else, it is said that the person has civil responsibility against the damaged. On this basis it may be concluded that responsibility is the perquisite to having authority. Therefore a free and wise human is aware of the consequences of his actions and is responsible for them. Considering this content it can be concluded that a person's responsibility for compensation of damages caused by his/her actions is a natural and accepted principle (Katoozian, 2009, p46).

It should also be taken into account that by sports, the purpose is not only entertainment, having a money-making job and or an honorable one; rather the final destination is promotion of health and chivalry spirits. This is also said that as the guarantee for adherence to civil rights, civil responsibility plays a very crucial and sensitive role in terms of asking for people's rights and resultantly regulation of social and legal relations. Responsibility is in different shapes and the most important ones are ethic and legal responsibilities. The former itself is divided into criminal responsibility and civil responsibility. Hereby, legal responsibility enforces compensation for damages.

Responsibility is what an individual is tasked with and is consisted of duties, actions and verbs. In other words it determined the sentence of the inflictor of damage regarding criminal and civil consequences of his/her actions. It is also defined as the legal commitment of an individual for compensation of damages inflicted on others. Whether this damage is caused directly by the individual or is caused as a result of an action of him/her.

Since there have been no specific regulations regarding civil responsibility of lifeguards and on the other hand, considering the expansion of championship sports and increased participation of legal and real entities in sports; disputes regarding compulsory guarantees in this context. Therefore, in the present paper we are trying to provide sufficient and suitable solutions for investigation of civil responsibility of lifeguards and managers against swimmers in order to clarify the existing ambiguities and fill the gaps.

\section{Lexical and Idiomatic Definitions of res- ponsible}

Who is a responsible person? It means someone is responsible against another and a person will be in state of civil responsibility when he/she has done a damaging act against the laws and is obligated to compensate the damage. Damages may be inflicted on someone as a result of liability or direct action of a person. However, in any case there should be an objective relationship between action or liability and the inflicted damage.

\section{Definition of civil responsibility}

Civil responsibility is defined as obligation for compensation of damages. In terms of legal actions, damages are inflicted by violation of agreements in contracts. On the other hand, sometimes legal facts are the source of responsibility. It means that responsibilities are created without any intention. Entire out of contract requirements are of this type. There are also times when 
law is the source of responsibility. It means that the law puts a responsibility burden on a person. Considering this content, in general sense, civil responsibility means compensation for damages. On this basis civil responsibility status is realized when person or persons have inflicted damages on others or have cause it by their actions. In other words, civil responsibility is defined as commitment for compensation of inflicted damages by the inflictor (Abasian, 2017, p5). In another definition of civil responsibility it can be said that it is defined as a commitments and or obligations that are set for legal and real entities based on religion, ethics, law and contracts. Therefore we are required to constantly consider for the ethic aspect of civil responsibility. In many cases, the basis of civil responsibility is founded on ethics. Considering this content it can be concluded that evaluation of civil responsibility with mere consideration for external criterions impedes justice. On this basis it is crucial to consider for ethical elements during evaluations (Badini, 2006, pp110-112).

\section{Specific definition of civil responsibility}

In more specific definitions, civil responsibility has been defined as a person's obligation for compensation of damages inflicted on others without the need for existence of a previous contract. The obligation caused by this type of responsibility is out of contract. Such obligations can be divided into three basic branches including:

A) Necessity of living a safe and nondetrimental life has been referred to in article 1 of civil responsibility and principle 40 of the constitution.

B) Necessity of respecting others' properties and rights. In this case responsibility may rise due to illegitimate standstill in others' properties.

C) Benefits, values and results of financial and intellectual work of a person belong to him/her. In this case responsibility may rise due to illegitimate use of other's ideas or belongings (Jalili, 2016, pp13-14).

\section{Management and responsibility of pools}

Pool manager: this is referred to the legal or real entity running a sport space by the help of one or multiple human workforces. In any swimming pool, whether being large or small, there is usually equipment which may be too simple or too modern that may require a certain level of expertise to be able to operate them. Despite the type of this equipment and the size of the swimming pools, there are always risks present in these spaces which may harm the users in different ways. A sport manager is responsible for both management of sport staff and equipment and a liability in any case results in rise of civil and or criminal responsibilities. On this basis, management of sports clubs is considered as one of the most specialized types of management in the field of sport.

\section{Basics of responsibility of pool managers and lifeguards against athletes and swim- mers}

Laws of Iran have accepted the theory of fault in many contexts while in some other contexts including work accidents and driving accidents, the theory of risk and the theory of guaranteeing individuals' rights have been selected. In fact when the goal is to benefit the public and social support issues are more effective, civil responsibility 
based on risk theory will be accepted.

In most cases in which an unfortunate and unpleasant accident takes place in a swimming pool and results in death or harm of a swimmer, according to laws, either of the lifeguard, the pool manager or both of them are considered as responsible for compensation of damages. In order to improvise for such situations managers must use insurances to cover the staff in order to be able to compensate for damages inflicted on swimmers.

The question that comes up is why and based on what basis the inflictor of damages on others is responsible for compensation of these damages? Several theories have been proposed in order to provide an answer for this question among which it can be referred to the theories of fault, risk, right guarantee and the mixed theory.

\section{Fault Theory}

In the context of damage compensation, one of the most important theories is the theory of fault. In this regard it can be said that the fault theory is the general principle of civil responsibility and in cases of absence of specialized principles, it is referred to the fault theory. This theory is in fact the basis of civil responsibility. Based on this theory, a person is responsible when he/she has committed a fault in his/her duties or actions. In fact the damaged or injured individual can only achieve his/her right when he/she is able to prove that the inflictor of the damage has committed an act which has inflicted the damage. Whenever a person is reluctant of taking necessary and conventional cautions during his actions and causes harm to others, this theory finds him/her irresponsible and the burden of proving the fault of the doer is on the shoulders of the damaged individual (Rahpeik, 2016, p37).

Sport instance: Considering that supplication of lifeguarding equipment including floating bubbles, rings, bars and life buoys and also boats for open sea spaces is the task of managers, those sport managers who violate their duties as swimming pool managers and cause swimmers harms due to defects in their facilities and equipment including gas leak, electricity and lack of suitability of coverage of the outer area of swimming pool are responsible for compensation of damages. Sporting spaces should have adequate contexts and equipment for providing help in case of possible accidents. This equipment includes existence of first aid kits, presence of trainers with knowledge in first aids and facilities for transferring injured people to caring units. As a result, in case of a horrible and harmful incident for a swimmer in which it is proven that one of the aforementioned factors has been the cause of accidents, the management of the swimming pool has a civil responsibility because of a fault of his/her.

Sport instance: in case of liability of a lifeguard against a swimmer who is drowning or in case of drowning of swimmers in absence of lifeguards where they have to be present, the lifeguard will be responsible for the incident. One of the duties of lifeguards is to be ready and present in the swimming space 15 minutes before entrance of swimmers. During their working time, they are not allowed to leave their post under any circumstances and if the lifeguard leaves his/her post, he/she will be responsible for the damages inflicted on swim- 
mers. In the context of jurisprudence, it has been said that if someone leaves his child with another to learn swimming and the child drowns, the coach or trainer is responsible for the death of the swimmer (Katoozian, 2009, pp14-15).

It is worth mentioning that solely acceptance of the fault theory is not currently sufficient for settlement of disputes and curing pains. This theory has certain defects which are as follows:

a) Difficultness of proving a fault and ambiguousness of the inflicted damage

b) Lack of synchronization with industrial and economic advances

With respect to results of the fault theory, there only a few people who can claim that responsibility should be only based upon fault and no other element is effective in this context. In addition development of responsibility insurances have reduced the attractiveness of many of reasons. Considering this information, the following could be stated as results of the fault theory. People who do not have authority including children and those who have lost their authority including injured people have no civil responsibility (Barikloo, 44). Another important conclusion drawn from the aforementioned theory is that the injured should prove the fault of the element of infliction of damage. Since it is originally believed that there is no fault, when the damaged person is not able to prove the fault of the inflictor of damage, the inflictor will not be considered responsible and the damage remains uncompensated (Hekmatnia, 2009, p44).

\section{Risk Theory}

The theory of risk was developed during the final years of $19^{\text {th }}$ century and simultaneous with industrial revolution. As a result of industrialization of societies and increase in related legal issues, the fault theory could no longer be suitable for all disputes (Michele, 1997, p41). According to the risk theory, such damages are considered as noncompensable and may remain uncompensated. This issue resulted in emergence of the risk theory in which the criterion of responsibility is an objective relation between the damaging act and the caused damage (Hoseini Nejad, 2013). According to this theory, fault is not the only condition for civil responsibility; rather whoever creates a potentially dangerous environment for the sake of his/her own benefits and causes harms or damages to others is responsible for the created damages. On the other hand, article 328 of civil law considers the agent of damage responsible for compensation and therefore this article can be explained based on the risk theory.

On this basis when the owner or manager of a swimming pool creates this potentially dangerous space for the sake of his/her own benefits, in case of occurrence of damages the owner or manager should compensate them. Based on this theory there is no need to prove the fault of the manager of owner. On the other hand, despite all of its desirable advantages, the risk theory has received criticisms to the extent that proponents of this theory have finally been forced to adjust this theory and propose a number of new theories which are termed as mixed theories.

\section{Mixed theories}

It is worth mentioning that there is no way that supports for justice in full terms. 
As it cannot be claimed that responsibility is only emerged as a result of a fault, the theory of risk also seems unreasonable in certain occasions. Therefore a group of people believe that the risk theory is only the basis of responsibility when a person benefits from it and creates a potentially dangerous space for collection of benefits. There also another group of people who believe that only activities will result in responsibility which are unusual and or unconventional (Katoozian, 2007, p202).

\section{Risk theory against benefits}

With respect to this theory it can be stated that nowadays swimming is no longer considered as only an entertainment and since it is also viewed as a serious sport and every day more and more people are oriented towards this sporting field due to extensive advertisements; more and more benefits are obtained by managers and owners of swimming pools. In this regard, whenever damage is inflicted on a swimmer the owner and manager of the swimming pool. In this context only those potentially dangerous activities are bound to civil responsibility by which the owner or the agent obtains benefits. Ethics and science have both agreed that whoever obtains benefits from a certain action, should also bare the associated damages. On this basis, not every activity results in responsibility, rather only activities that result in benefaction of the owner create civil responsibility (Hekmatnia, 2009, pp75-76).

\section{Unconventional work theory}

According to this theory, the criterion of responsibility is conventionality of works done in a way that if someone is damaged due to unconventional works of another, a civil responsibility case would be present. In terms of activities that cause harms and damages to others, civil responsibility would emerge only if the activity is unconventional (Jalili, p20).

\section{Right Guarantee Theory}

Stark has proposed this theory as the basis of civil responsibility. According to this theory, the basis of civil responsibility is not exclusive and limited to the either of fault or risk theories. In this theory not only attention is paid to effects and evaluation of act of the agent of damage; but also the lost advantages or benefits of the damaged person are considered for and efforts would be made for guaranteeing the rights of the damaged person.

This theory emphasizes on guaranteeing of rights of damaged or harmed individuals in a way that not only it is applied for disadvantages, but also it is applied for certain affairs including responsibilities due to usurpation and etc. despite the relationship between the act and the caused damage, the legislator considers the agent of harm as responsible for compensation of damages because the legislator is after guaranteeing the damaged persons' rights. According to this theory every person has the right to live in a healthy and safe society in a way that rights of all individuals are considered for. In this case, as soon as a right is violated, the violator or the agent of harm should compensate it. This compulsory compensation is the same as civil responsibility (Katoozian, 2011, p208). In this theory a person's right on his/her physics and his/her right on his/her entire properties 
are considered as the primary rights of every individual and in case of a violation of these rights, the violated person should be supported. In this regard the state is also obliged to provide suitable mechanisms towards realization of this support (Ghasemzadeh, 2007, p320).

\section{Scope of civil responsibility of pool mana- gers and lifeguards}

Sporting activities may cause physical harms to athletes. Some of these harms are due to violation of contractual obligations and some others are also occurred without any previous contracts.

\section{Contractual responsibility}

Contractual responsibility is defined as the responsibility of a person who have committed upon a certain act according to a contract. If the person inflicts damage on the other side of the contract as a result of restraint of a commitment or a delay, the person is responsible and obliged for compensation of inflicted damages. Contracts between individuals show what they are obliged to do and violation of any of these commitments results in civil responsibility or in some cases, even criminal responsibility (Ramezani, 2016, p4).

\section{Compulsory or non-contractual responsibi- lity}

This type of responsibility is special to cases in which a person refuses to adhere to his/her legal and or principal commitments and causes harm to another person as a result. In terms of compulsory liability, the source of responsibility is the law instead of contracts. Therefore the agent of damage may result from the fault of the trainer which is further resulted in his/her compulsory responsibility for compensation of inflicted damages. In addition in Imams jurisprudence it has been stated that civil responsibility of sport coaches including lifeguards are set based on regulations and faults of the trainer him/herself.

The question that comes up here is what is the type of created responsibility when a person is damaged or harmed while swimming in a pool? From the view of the author, this type of responsibility must be compulsory because there are no written contracts between the users and owners of swimming pools. However in cases in which there is a specific contract, the responsibility of the manager of the swimming pool will be of contractual type.

The other question that comes up is what is the type responsibility for compensation of damages occurred during the contract? As an answer, it must be said that in this case, the created responsibility is compulsory since the damage has been caused during implementation of the contract and is not yielded due to lack of implementation.

In order to be able to recognize if the inflicted damage is due to violation of contractual agreements or not, the entire articles and subjects of the contract should be collected and studied. In this case it makes no difference whether the articles and subjects of the contract have been developed and written by the sides of the contract or by a legal reference. In addition, in terms of affairs that are either associated with conventions or associated with justice, violation results in contractual responsibility. This result is concluded from articles 220 and 225 of the civil code. Ultimately it must 
be stated that all legal and real entities involved with sporting, not only are obliged to consider for contractual agreements, but are also responsible for adherence to out of contract obligations.

\section{Conditions for realization of civil responsi- bility of managers and lifeguards}

The main purpose of civil responsibility is to fully compensate for inflicted damages and harms. In order to realize this, certain conditions are necessary which are investigated under the title of conditions for realization of civil responsibility. These conditions include:

\section{A) Existence of loss:}

Loss is defined as a damage or elimination of benefits. Therefore a loss may be due to destruction of a property are elimination of a benefit that is caused by implication of the commitments (Jafari Langroodi, 2006, p415). Existence of loss is crucially important for realization of civil responsibility. This is because existence of loss is exclusive to civil responsibility and this is what differentiates civil responsibility from criminal responsibility and ethical responsibility (Hoseinnejad, p35).

Sport instance: in case damage is inflicted on swimmers as a result of defects in equipment or lack of suitability of the floor of the swimming pool, it is said that a loss is occurred. However this loss has certain conditions which are as follows:

1. The damage must be objective

2. The inflicted damage must be direct. Directness of the damage means that there should be no other incidents between the damaging act and the inflicted damage. In other words by di- rectness of loss it is not meant that there should be no other factors involved in infliction of the damage, rather it is the criterion for identification of a causal effect between the damaging act and inflicted damage.

3. The damage must be in result of harm to the right of a person.

4. The damage must be previously uncompensated. This is because we cannot add several damage compensation systems to each other.

5. The person who files the argument must either be the harmed person or his/her advocate.

6. The loss must be predictable and the criterion for predictableness of a loss is the conventional criterion.

\section{B) Existence of a damaging act}

In Iranian laws, it is basically prohibited to cause harm and or damage to others; unless there are factors and or elements that relieve a human being from his/her responsibilities. In this regard, for realization of civil responsibility there needs to be a damaging act present. Without a damaging act, nothing can be proved. On this basis, in addition to being based on fault and risk theories, existence of a damaging act is a perquisite for realization of civil responsibility (Katoozian, 2009, p15). It has been widely accepted that humans are responsible for their actions and behaviors, however sometimes leaving an act may result in civil responsibility or even criminal responsibilities. These acts include manager's reluctance in reporting financial violations and or crimes and a lifeguards' reluctance in saving a swimmer who is drowning. In cases in which a swimmer drowns because the lifeguard had left his/her post; leaving the act 
results in lifeguards' civil responsibility.

There are also instances of this issue in subjective laws. Among these it can be referred to the law of reluctance of helping injured people and elimination of life threats issued in 1976. According to the first article of this law, whoever watches a person in danger of death or injury and refuses to help or call for help, will face a jail time of one year and some cash fine as well. On the other hand, if the person is someone whose job makes him/her able to provide a significant help but refuses to provide this help, he/she may be imprisoned between 3 months to two years as well as being obliged to pay a certain amount of cash fine.

\section{c) Existence of a causality relationship between the damaging act and the inflic- ted damage}

By a causality relationship it is meant that a relationship must exist between the inflicted damage and the damaging act. It would be senseless to consider someone responsible for a damage in which he/she had no participation. However it is a fairly difficult job to determine the existence of a causality relationship. This is because there are various different factors which may be influential in infliction of damage. Against swimmers who swim in pools, if the inflicted damage is due to fault of the manager, the responsibility would be with the manager. This fault may be due to liability in helping injured athletes or making use of nonstandard and unsafe equipment. For example, if hygienic problems and or pollution of the pool water cause harm, the pool manager must be considered responsible for compensation of that damage. However if a damage is inflicted on a swimmer as a result of liability of the lifeguard, the lifeguards fault will be considered as the main cause of damage and the lifeguard will be responsible for compensation. Another question that comes up in this regard is if acting reluctant of helping injured people in sporting spaces is a crime or that it only results in civil responsibility? According to the related article, those who act reluctant of helping injured people will face a jail sentence of one to three years without even having caused the damage. The reason for this punishment is acting reluctant of providing the help that was issued by the law. On this basis, indifference of managers, coaches, arbitrators and or lifeguards against injured people results in significant responsibilities.

\section{Plurality of causes}

In some damages, there are more than one people involved. This issue has been known as plurality of causes and therefore, in some cases it is not easy to identify the causality relationship. On the one hand every civil responsibility related issue requires a clear causality relationship. It is the duty of the damaged person to prove the aforementioned causality relationship (Taghizadeh et al. 2015, p101). On this basis plurality of causes may rise because of plurality of longitudinal causes, plurality of transverse causes and or plurality of human agents with compulsory and natural agents.

\section{Transverse causes}

Whenever more than one people collaborate in occurrence of a damaging act, their plurality will be of transverse type. For example, whenever as a result of liability of two lifeguards at two sides of the pool someone drowns while swimming, the type of 
plurality of causes is transverse. There are four approaches for responsibility of transverse causes which include:

A: equality of responsibilities: in case of transverse cause plurality type, determination of the responsible cause is not an easy task because the incident could be assigned to any of the causes and a causality relationship exists between the act and the result. For this purpose, transverse cause plurality in the views of jurists is considered as participation in crime and all those who participated in a crime are considered responsible. On this basis, regarding transverse causes' responsibility, it is generally accepted that is the effects of causes are similar and equal; the responsibilities must also be divided between them equally and similarly. The reference for this statement is article 533 of the Islamic punishment laws that has stated: whenever two or more people cause a crime or damage on others, they are both responsible equally (Najafi, 1995, p57). B: responsibility based on effect of each cause: in this case, responsibility is divided between actors with respect to importance of effects of acts of each one. The reference to this statement is article 526 of the Islamic Punishment laws that has stated: whenever there are more than one people involved in a crime in different ways, the responsibilities will be divided based on the extent of influences of act of each individual and every person is responsible according to the effect of his/her act (Jalili, pp43-44).

$\mathrm{C}$ : responsibility based on the degree of fault: in terms of this approach, the degree of fault of some causes may be higher and some may be lower in this context.

D: Guaranteed responsibility: except for special conditions, this type of responsibility is not accepted in Iranian laws.

\section{Longitudinal Causes}

Whenever in an accident, one or more causes are effective in a respective order, in this case it is said that a longitudinal plurality of causes has taken place. In this regard, several different approaches have been proposed which include: theory of primary cause, theory of equality of causes, theory of dynamic cause, theory of distribution of guarantee with respect to ratio of effectiveness, theory of conventional and main causes and the theory of close and direct cause.

\section{Glancing causes}

In cases in which damages are inflicted, sometimes there is a glancing knowledge about infliction of damage by one of the multiple causes but the mentioned cause is not objectively identifiable. The reference for this statement is the article 477 which states that in case there is no doubt, the owner of the right can ask the suspect to swear an oath. In case of a murder, the wergild is paid by the government and in cases other than murder; the damage should be compensated by the suspects in equal portions. Whenever the source of the glancing knowledge is confession of suspects, the parents or the damaged $\mathrm{him} /$ herself is free to ask any of the suspects for compensation of damages. In this case there is no difference between intentional and unintentional crimes.

\section{Plurality of humane agents with compul- sory and natural factors}

In cases in which damages are inflicted 
due to plurality of human agents with natural elements, the responsibility of the incident is with the human agent and the effect of natural element would not be considered for (Katoozian, p471).

\section{Effects of civil responsibility}

One of the most important effects of civil responsibility is the obligation for compensation of damages. In terms of the former, it is important to return the situations to their pre-accident status. For this reason, there are different ways for compensation of damages in different cases. For instance, in case of land usurpation, the usurper is obliged to return the whole land to the owner and if it was not possible to return the property, its current financial value should be paid to the owner. But in case damage is inflicted on a swimmer as a result of liability of a lifeguard or defects of equipment, the compensation required is usually based on payment and taking responsibility for treatment costs. In case the swimmer dies the case is either intentional or semi-intentional and a certain procedure is considered for each case.

\section{CONCLUSION}

Nowadays, there can't be any social activities found free from civil responsibility. On this basis civil responsibility is defined as legal commitment of a person for compensation of a damage inflicted on another person. Whether this damage is directly caused by the individual or caused by his/her actions. On this basis, nature of civil responsibility is based on compensation of damages and it has been widely accepted that whenever someone inflicts damage on ano- ther, the inflictor of the damage is obliged for compensation. Civil responsibility arises when someone harms another. In any case in which a person is found obliged to compensate for damages inflicted on another person, it is said that the damage inflictor has a civil responsibility. Here it is worth mentioning that in terms of civil responsibility, the criminal face of affairs is substituted with damage compensation.

It seems that for pool managers, civil responsibility is basically based on risk theory. Because they obtain benefits through foundation of such potentially risky and dangerous spaces and therefore, they are responsible for damages caused to swimmers. On the other hand, responsibility of lifeguards is solely based on fault theory and in these cases the lifeguard is directly responsible for compensation of damages inflicted on athletes and or swimmers. On the other hand, since the main purpose of civil responsibility is to fully compensate for damages, in cases a damage is inflicted on a swimmer or a swimmer dies while swimming in a pool, the fault is both on the manager and the lifeguard and they would be considered responsible for compensation. In order to improvise for such situations managers must use insurances to cover the staff in order to be able to compensate for damages inflicted on swimmers.

\section{REFERENCES}

Ashtari, M. et al. Civil responsibility: Tehran, 2013.

Badini, H. Philosophy of civil responsibility: Sahami Enteshar, Tehran, 2006.

Barikloo. A. Civil responsibility: Hoghooghdan, Tehran, 2010.

Ghasemzadeh S.M. Principles of civil res- 
ponsibility: Dadgostar Nashr, Tehran, 2007. Hekmatnia. M. Civil responsibility in Imam Jurisprudence: Islamic sciences and knowledge research center, Tehran, 2009.

Jalili A. Advanced course of legal events and civil responsibility: Sharif, Tehran, 2016.

Katoozian. N. Out of contract obligations: TUP, Tehran, 2006.

Katoozian. N. Athletic fault and athletic responsibility: Aiden, Tehran, 2015.

Langroodi. M. J. Terminology of law: Ganj e Danesh, Tehran, 2006.

Najafi. M. H. Javaher-Alkalam: Dar-olkotob Islamic, 1995.

Ramezani B. Civil responsibility of building contractors against employers: Tehran, 2016.

Rahpeik H. Civil responsibility rights and compensations: Khorsandi, Mashad, 2011. Taghizadeh. I. Civil responsibility: PNU, Tehran, 2015.

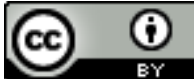

License information: This is an openaccess article distributed under the terms of the Creative Commons Attribution License, which permits unrestricted use, distribution, and reproduction in any medium, provided the original work is properly cited.

Article received on October 29, 2017.

Evaluated August 01, 2018.

Accepted on February 17, 2019.

Published on February 28, 2019.

How cite this article (ABNT):

BASHIRI, Akbar; RAMAZANI, Behnam; ZADEH, Mahdi Mohammad. Investigating the Civil Responsibility of Managers and Lifeguards against Swimmers. Estação Científica (UNIFAP), Macapá, v. 8, n. 2, p. 81-92, may/apr. 2018. 